Proceedings

\title{
Representation of Joint Patterns in HD SEMG: A Case Study ${ }^{+}$
}

\author{
Iva Milerská 1,2,*,ł,\$, Elizaveta Saifutdinová 2,\$, Marek Jelínek ${ }^{3, \S}$ and Lenka Lhotská ${ }^{2,4, \S}$ \\ 1 Department of Cybernetics, Faculty of Electrical Engineering, Czech Technical University in Prague, \\ 16627 Prague, Czech Republic \\ 2 The Czech Institute of Informatics, Robotics and Cybernetics, Czech Technical University in Prague, \\ 16000 Prague, Czech Republic; saifueli@fel.cvut.cz (E.S.); lenka.lhotska@cvut.cz (L.L.) \\ 3 Faculty of Health Studies, Jan Evangelista Purkyně University in Ústí nad Labem, 40096 Ústí nad Labem, \\ Czech Republic; marek.jelinek@ujep.cz \\ 4 Faculty of Biomedical Engineering, Czech Technical University in Prague, 27201 Kladno, Czech Republic \\ * Correspondence: novotiv1@fel.cvut.cz; Tel.: +420-602-295-478 \\ + Presented at the 13th International Conference on Ubiquitous Computing and Ambient Intelligence UCAmI \\ 2019, Toledo, Spain, 2-5 December 2019. \\ ‡ Current address: CIIRC, Jugoslávských partyzánů 1580/3, 16000 Prague, Czech Republic. \\ $\S$ These authors contributed equally to this work.
}

Published: 20 November 2019

check for updates

\begin{abstract}
Investigation of joint patterns is one of many ways to detect soft tissue pathology. Functional blockage of the joint is a common clinical term that expresses one of the most common functional disorders in the musculoskeletal system. In this paper, we focus on HD SEMG signal processing with artificially induced joint blockage using reflective heel pad. Four bipolar electrodes were placed on the muscle vastus medialis and six on the muscle rectus femoris. One proband (male, 46 years) sat on the chair with the knee joint fixed at $70^{\circ}$ flexion and hip at $120^{\circ}$ between the pelvis and the femur, which corresponds to a relaxed sitting position. HD SEMG signals were recorded during three isometric maximum voluntary contractions of the knee extensors. The first data set of three contractions was measured without heel pad and the second and third data set with using pronation and supination heel pad respectively. Results show that stabilization of the knee is eliminated by fixing the leg in the chair and the muscle vastus medialis has only extension function without using heel pad. Thus, the contraction begins with activation of the muscle rectus femoris, which only has an extension function and then the muscle vastus medialis is added to the contraction. If we use the heel pad, the muscle vastus medialis stabilizes the knee and the contraction begins simultaneously with the musle rectus femoris.
\end{abstract}

Keywords: HD SEMG; joint patterns; functional blockage; reflective heel pad; muscle timing

\section{Introduction}

Investigation of joint patterns is one of many ways to detect soft tissue pathology. It is an examination of the joint mobility of a given joint. Limiting this momentum indicates damage to structures that affect the performance of isolated motion in the joint. So-called articular blockages can result in reactive changes in skeletal muscle tension. These changes could be detected by surface electromyography (SEMG). The measurement using High density SEMG (HD SEMG) was proposed based on the results of the previous experiment [1,2].

The paper explains our preliminary results in study of muscle activity in knee extension. We provide analysis of muscle activation patterns for extension with different types of heel pad. The quadriceps femoris muscle is the great extensor of the knee. This muscle consists of four parts: 
rectus femoris, vastus lateralis, vastus medialis, and vastus intermedius. Rectus femoris is located in the middle, while vastus lateralis forms the bulk of the lateral thigh, vastus medialis is in the medial thigh, and vastus intermedius lies deep to the rectus femoris between vastus lateralis and medialis. Rectus femoris is a particular muscle (it is also a flexor muscle at the hip joint) while the other components are monoarticular muscles [3]. Therefore, it is expected that the different morphological and dynamic behavior of the quadriceps components would cause these muscles respond differently to artificially induces joint blockages by a reflective heel pad. The muscles rectus femoris and vastus medialis were selected for this purpouse by using HD SEMG.

\section{Functional Blockage}

Functional blockage of the joint is a common clinical term that expresses one of the most common functional disorders in the musculoskeletal system. It can be defined as a malfunction that is not accompanied by a structural disruption of the joint. The total range of motion does not change with the functional joint block, but there is a relative change in the magnitude of the partial movements that make up the total motion around one joint axis [4]. According to Velé [5], joint motion is a small movement in the joint in another direction than those directions typical of its function. Loss of joint clearance is manifested by stiffness in the joint and deterioration of joint mobility. The articular clearance is defined by the elasticity of the articular capsule and the pull of the short muscles that clamp around the joint and act parallel to the axis of the movable segment [5].

Lewit [6] divides joint blocking symptoms to limit joint movement, loss of joint clearance, and reactive changes in skeletal muscle tension that cross the blocked joint and perform active movement there. Joint blockades have a high tendency to chaining. In this way, the flexion or extension chains of joint dysfunctions arise in the limbs. On the lower limb, these chains are caused by many causes, such as defective pelvis position, and traumatic conditions of the hip, knee and ankle.

The examination of the articular barriers according to Rychlíková [7] consists in delaying the bones that form the joint and subsequently in shifting the bones to one another. It is, therefore, an examination in non-physiological ways, when movements are performed passively. The examination of the joint in physiological directions, i.e., in flexion or extension, is dealt with by Tichý [4]. In this examination, skeletal muscles are much more pronounced, and in addition to the other soft tissues that cover the joint (fascia, subcutis, skin). Hypertonus or skeletal muscle spasm will most likely affect the position of the physiological joint barrier and the size of its joint will be based on the assumption that skeletal muscle tension changes in joint blockages.

\section{Materials and Methods}

\subsection{Subject}

One healthy proband (male, 46 years) was randomly selected to conduct this experiment. Information to this study was provided before examination by a physiotherapist. Medical history provided information about the dominant lower limb and functional examination. Any bacterial inflammation or neurological rewiring reflex activity in the dominant lower limb was recorded.

\subsection{Data Acquisition}

Measurements were carried out on the previously designed chair [2]. The angle of the knee joint was fixed at $70^{\circ}$ flexion and hip at $120^{\circ}$ between the pelvis and the femur, which corresponds to a relaxed sitting position. Eight electrodes were placed on the proband's dominant lower limb on vastus medialis (channels Ch1-Ch4) and twelve on rectus femoris (channels Ch5-Ch10) with bipolar electrode connection (shown in Figure 1). Selected SEMG signals were recorded during three isometric maximum voluntary contractions of the knee extensors with two minutes rest between contractions. First one consisted of extension without heel pad (WHP). The second and third one used pronation (PHP) and supination heel pad (SHP) respectively. 
a)

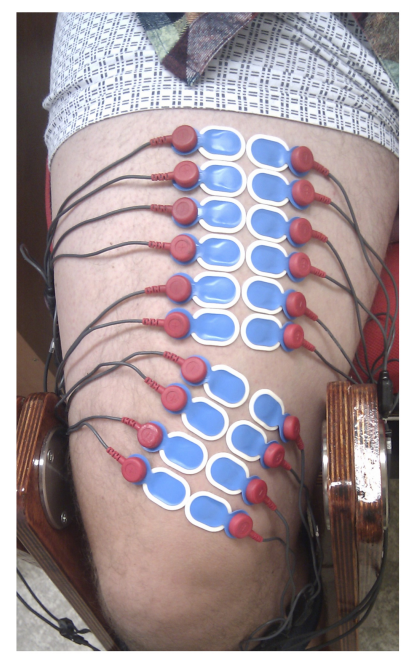

b)

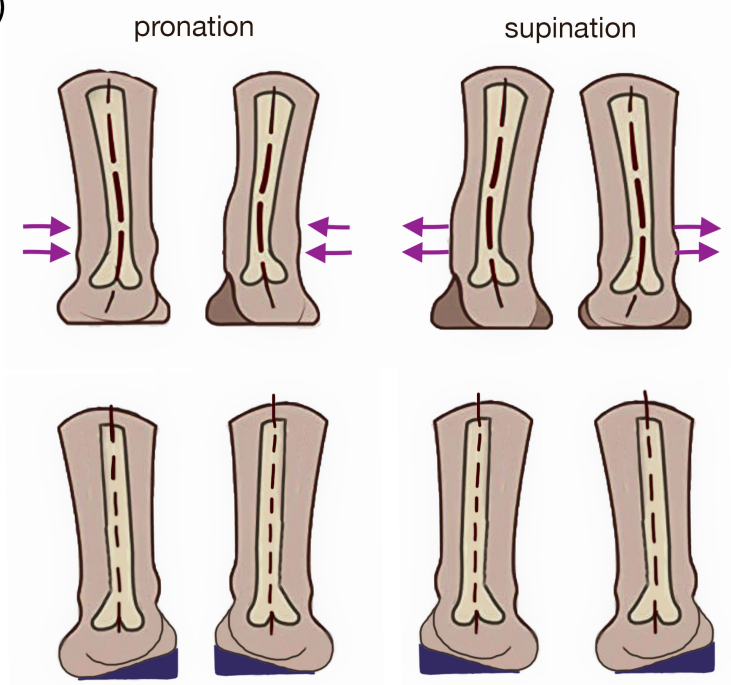

Figure 1. (a) Bipolar connection of electrodes and its placement on the muscle vastus medialis and rectus femoris. (b) Pronation and supination of the ankle and the example how to use the heel pad.

\subsection{Signal Processing}

Signals from all channels were processed by algorithms implemented in Matlab environment. First, each signal was filtered by using Butterworth bandpass filter of second order with cutoff frequency 20 and $350 \mathrm{~Hz}$, respectively. The envelope after rectification was calculated using a moving average method with $0.4 \mathrm{~s}$ window. The threshold used to get the contractions is one standard deviation (SD) of the whole signal. Because this start depends on the threshold size and is different for each signal, we used the method similar to the study [8]. We created a slope line from the point where threshold crosses the envelope (it is the position where the signal falls below the threshold) to $1 \mathrm{~s}$ before this point and looked for the maximum difference between the slope line and the signal envelope for detection of the contraction start. Figure 2 shows an example of how the measurement is performed to assess the start of the contraction.

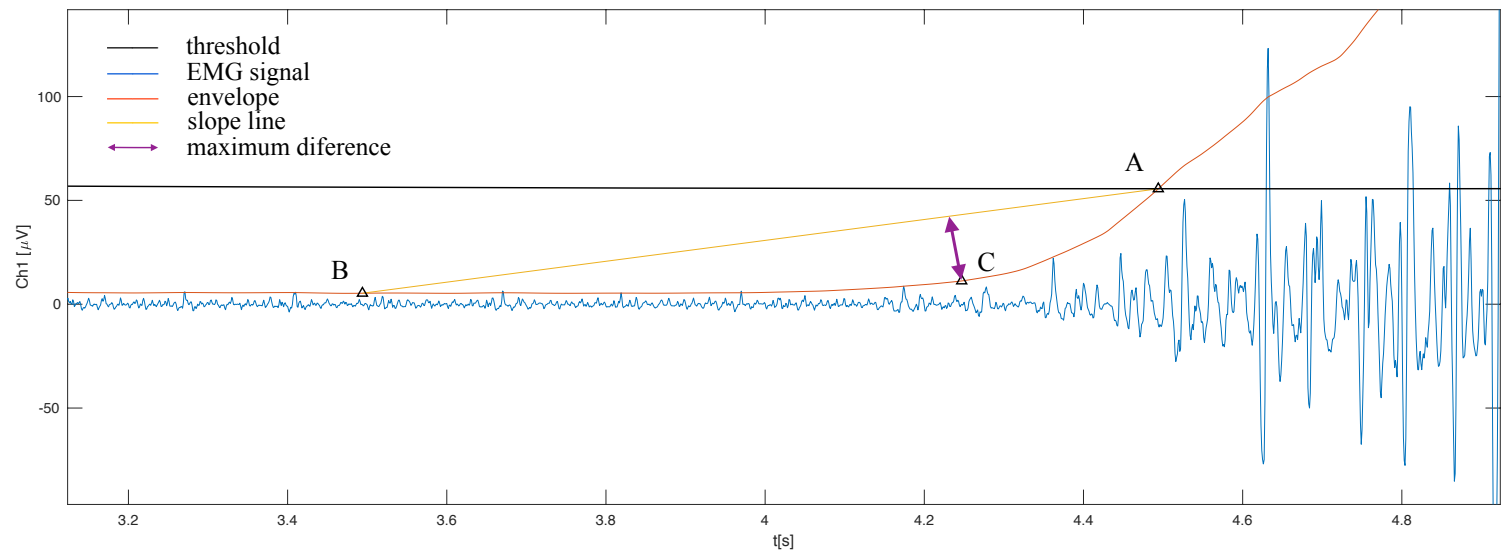

Figure 2. Method for estimation of contraction start (point C). After selecting the peak where threshold crosses the envelope (point A) and a line from this point to the position $1 \mathrm{~s}$ before (point B) is created. Then the differences between the line and the signal envelope are calculated and the position where the difference has its maximum is the start of contraction. 
This method was applied to all channels (Ch1-Ch4 vastus medialis, CH5-Ch10 rectus femoris) and all contractions. The starts of contraction are linked for better visual evaluation. An example of it is shown in Figure 3.
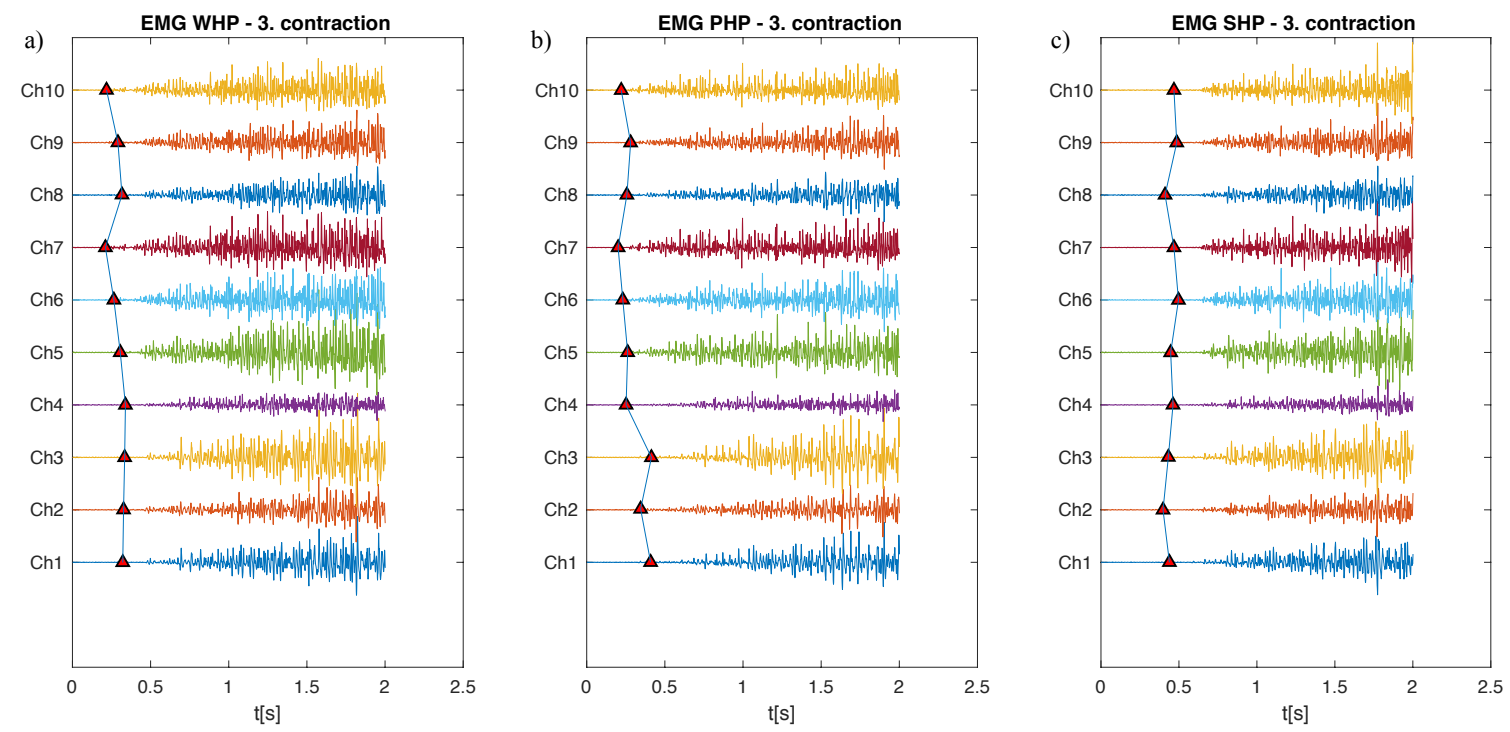

Figure 3. Example of start position of third contraction on the channel (Ch1-Ch4 vastus medialis, Ch5-Ch10 rectus femoris). (a) Start of contraction without using heel pad (WHP), (b) start of contraction with pronation heel pad (PHP), (c) start of contraction with supination heel pad (SHP). Red triangles represent the start of contraction. These point are linked by blue line for better visual evaluation.

\section{Data Analysis}

Because the specific topic in this study was to investigate the joint pattern and the muscle timing, it was necessary to find out the way how to explain the result.

Contraction starts in all channels represent muscle activation pattern. The first order polynomial model was chosen to investigate these patterns. For each contraction we fit this model in the least-squares sense. Then, the mean approximation curve was calculated for each type of measurement (WHP, PHP and SHP). Since the data was measured on one proband only, it is not possible to prove statistically significant changes. Based on these results, contraction starts were sorted from the fastest channel to the slowest one and represented in Table 1.

Table 1. The positions of contraction (con) starts sorted from the fastest channel. WHP: without using heel pad, PHP: pronation heel pad, SHP: supination heel pad.

\begin{tabular}{ccccccccc}
\hline \multicolumn{3}{c}{ WHP } & \multicolumn{3}{c}{ PHP } & \multicolumn{3}{c}{ SHP } \\
\hline 1.con [s] & 2.con [s] & 3.con [s] & 1.con [s] & 2.con [s] & 3.con [s] & 1.con [s] & 2.con [s] & 3.con [s] \\
\hline $4.134^{7}$ & $10.591^{7}$ & $16.811^{7}$ & $1.475^{4}$ & $7.748^{4}$ & $14.701^{7}$ & $1.773^{4}$ & $6.992^{8}$ & $12.598^{2}$ \\
$4.135^{10}$ & $10.595^{10}$ & $16.818^{10}$ & $1.486^{8}$ & $7.804^{8}$ & $14.721^{10}$ & $1.834^{2}$ & $6.993^{2}$ & $12.611^{8}$ \\
$4.178^{6}$ & $10.608^{6}$ & $16.865^{6}$ & $1.497^{2}$ & $7.807^{7}$ & $14.731^{6}$ & $1.834^{7}$ & $7.022^{5}$ & $12.632^{3}$ \\
$4.195^{9}$ & $10.626^{9}$ & $16.891^{9}$ & $1.515^{7}$ & $7.810^{10}$ & $14.752^{4}$ & $1.834^{10}$ & $7.041^{7}$ & $12.639^{1}$ \\
$4.208^{5}$ & $10.637^{1}$ & $16.906^{5}$ & $1.516^{1}$ & $7.812^{1}$ & $14.757^{8}$ & $1.842^{9}$ & $7.043^{10}$ & $12.647^{5}$ \\
$4.212^{8}$ & $10.642^{3}$ & $16.917^{8}$ & $1.520^{10}$ & $7.823^{2}$ & $14.762^{5}$ & $1.846^{1}$ & $7.054^{4}$ & $12.662^{4}$ \\
$4.216^{4}$ & $10.648^{2}$ & $16.922^{1}$ & $1.527^{3}$ & $7.828^{6}$ & $14.781^{9}$ & $1.846^{3}$ & $7.063^{3}$ & $12.668^{7}$ \\
$4.235^{2}$ & $10.652^{4}$ & $16.927^{2}$ & $1.546^{6}$ & $7.831^{3}$ & $14.845^{2}$ & $1.859^{6}$ & $7.063^{9}$ & $12.668^{10}$ \\
$4.247^{1}$ & $10.661^{5}$ & $16.934^{3}$ & $1.546^{9}$ & $7.839^{9}$ & $14.909^{1}$ & $1.871^{5}$ & $7.070^{1}$ & $12.686^{9}$ \\
$4.255^{3}$ & $10.664^{8}$ & $16.939^{4}$ & $1.550^{5}$ & $7.867^{5}$ & $14.914^{3}$ & $1.895^{8}$ & $7.077^{6}$ & $12.697^{6}$ \\
\hline
\end{tabular}

$1,2, \overline{3,4}$ Number of the channel on the muscle vastus medialis; $5,6,7,8,9,10$ Number of the channel on the muscle rectus femoris. 


\section{Results}

The start positions of contraction on all channels were interleaved with a straight line using the least squares approximation (the example is shown in Figure 4).

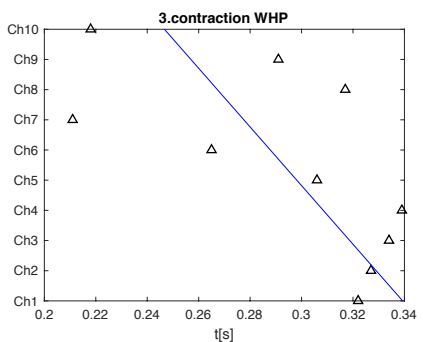

(a)

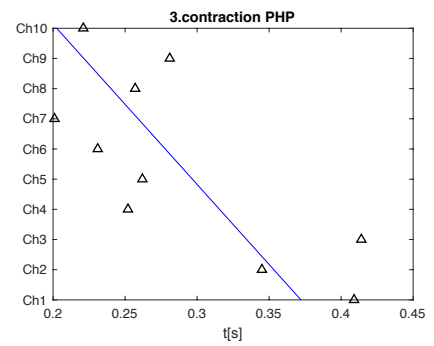

(b)

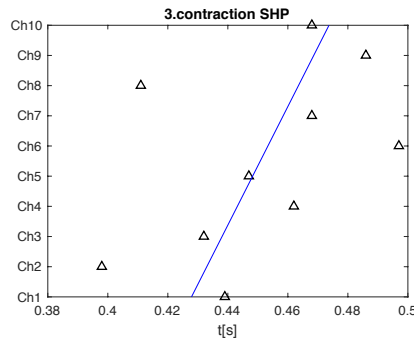

(c)

Figure 4. Example of start position of third contraction on the channel (Ch1-Ch10) and approximation curve. (a) Start of contraction without using heel pad (WHP), (b) start of contraction with pronation heel pad (PHP), (c) start of contraction with supination heel pad (SHP).

The mean approximation curve was calculated for contraction without using heel pad, with pronation and supination heel pad. Mean approximation curve is shown in the Figure 5.

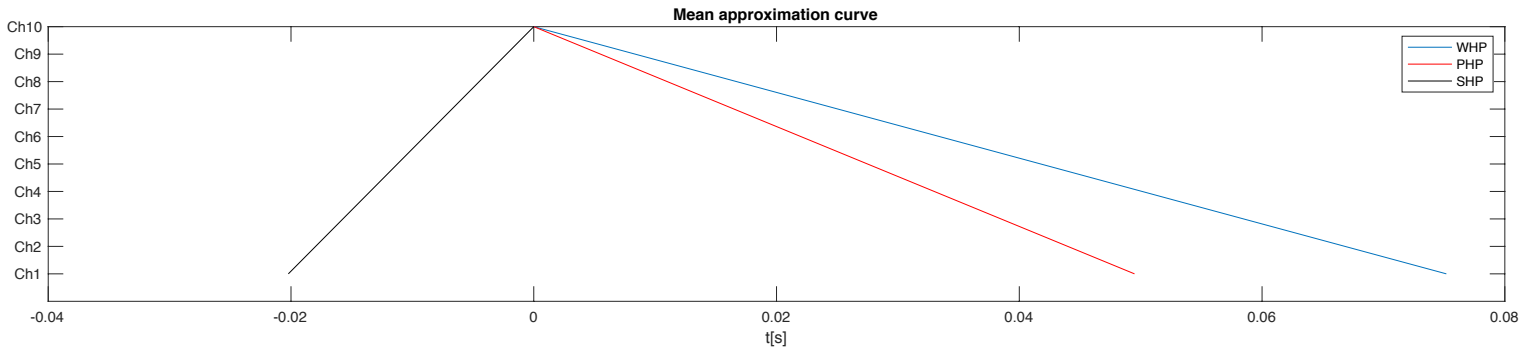

Figure 5. Mean approximation curve without using heel pad (WHP, blue line), with pronation heel pad (PHP, red line) and supination heel pad (SHP, black line)

The slope of the mean approximation curves without using heel pad and with pronation heel pad is similar. The mean approximation curve with supination heel pad has a reverse slope. These results indicate that the muscle rectus femoris starts the contraction in the cases WHP and PHP and vastus medialis starts contraction with SHP.

The start positions of contraction were sorted from the fastest channel for better understanding of the result. The results are more clearly interpreted in the table (Table 1). Mucle rectus femoris is faster in all three contractions and the SEMG signal spreads in the same way. Muscle vastus medialis is slower than rectus femoris. A signal propagation is more complicated in the cases with using pronation and supination heel pad and the muscles mutually cooperate.

\section{Discussion and Conclusions}

This study deals with timing analysis and HD SEMG signal propagation on the muscle vastus medialis and rectus femoris.

Three measurements were carried out (without heel pad, with using pronation and supination heel pad) on the previously designed chair. The angle of the knee joint was fixed at $70^{\circ}$ flexion and hip at $120^{\circ}$ between the pelvis and the femur. The electrodes were placed on the muscle vastus medialis and rectus femoris. HD-SEMG signals were recorded during three isometric voluntary contractions of the knee. Desired three muscle contraction on all ten channels were apparent after filtration without evidence of greater interference.

Firstly, one standard deviation was used as the threshold for the detection of contraction starts. Then a slope line was calculated from the point where threshold crosses the signal envelope to the 
point $1 \mathrm{~s}$ before. The new position of contraction was calculated as the maximum difference between the slope line and the signal envelope.

Muscle quadriceps femoris (with patella and ligament patellae) is the only knee extensor. Muscles vastus medialis and vastus lateralis have an extension and stabilization function. Muscles vastus intermedius and rectus femoris have only extension function.

The need for knee stabilization is eliminated by fixing the leg in the chair in a position corresponding to the relaxed sitting position and without using heel pad. Thus, in the beginning, it is not necessary to stabilize the knee and the vastus medialis muscle will engage the extension function to assist the muscle rectus femoris in contraction. When using the heel pad, the knee is artificially destabilized and the vastus medialis muscle performs both stabilizing and extension functions, which our results match (Table 1).

The described research was a pilot study that had as its main aim to prove the feasibility of the proposed experiment and successive data analysis. Although the tests were performed on one subject, they are promising. Based on these results, a multichannel electrode with $10 \mathrm{~mm}$ symmetric distances around $5 \mathrm{~mm}$ centre gab was designed. New experiments with more subjects are planned as the next step of this research.

Funding: This research was funded by CVUT institutional resources SGS grant number SGS17/216/OHK4/3T/37.

Conflicts of Interest: The authors declare no conflict of interest.

\section{Abbreviations}

The following abbreviations are used in this manuscript:

$\begin{array}{ll}\text { SEMG } & \text { Surface electromyography } \\ \text { HD SEMG } & \text { High density surface electromyography } \\ \text { Ch1-Ch10 } & \text { Channels number from one to ten } \\ \text { WHP } & \text { Measurement without using heel pad } \\ \text { SHP } & \text { Measurement with supination heel pad } \\ \text { PHP } & \text { Measurement with pronation heel pad } \\ \text { SD } & \text { Standard deviation }\end{array}$

\section{References}

1. Novotná, I.; Křemen, V.; Čeřovský, Z.; Hrach, K.; Jelínek, M.; Tichý, M.; Lhotská, L. 53. Representation of joint patterns in surface EMG. Clin. Neurophysiol. 2014, 125, e42, doi:10.1016/j.clinph.2013.12.091.

2. Novotná, I.; M. Holub, V.K.; Čeřovský, Z.; Hrach, K.; Jelínek, M.; Tichý, M. Př́ipadová Studie: Kloubní Vzorce při Využití Povrchového EMG; Creative Connections: Prague, Czech Republic, 2014; pp. 173-182.

3. Ozturk, N.; Begovic, H.; Demir, P.; Yagcioglu, S.; Can, F. Rectus Femoris and Vastus Medialis Muscles Exhibit Different Dynamics in Processing of Isometric Voluntary Contractions: A Fractal Analysis Study. In Proceedings of the 2019 IEEE International Symposium on Medical Measurements and Applications (MeMeA), Istanbul, Turkey, 26-28 June 2019; pp. 1-6, doi:10.1109/MeMeA.2019.8802161.

4. Tichý, M.; Jelínek, M.; Macková, E. Funkční blokáda kloubu a její příznaky. Kontakt 2010a Roč 2010, 12, 472-479.

5. Véle, F. Kineziologie: Přehled Klinické Kineziologie a Patokineziologie pro Diagnostiku a Terapii Poruch Pohybové Soustavy; Triton: Prague, Czech Republic, 2006.

6. Lewit, K. Manipulační Léčba v Myoskeletální Medicině; Sdělovací Technika: Prague, Czech Republic, 2015.

7. Rychlíková, E. Manuální Medicina: Prưvodce Diagnostikou a Léčbou Vertebrogenních Poruch, 3rd ed.; 530 s, Technical Report; Maxdorf: Praha, Czech Republic, 2004; ISBN 80-7345-010-0.

8. Zhou, S.H.; Helfenbein, E.D.; Lindauer, J.M.; Gregg, R.E.; Feild, D.Q. Philips QT interval measurement algorithms for diagnostic, ambulatory, and patient monitoring ECG applications. Ann. Noninvasive Electrocardiol. 2009, 14, S3-S8.

(C) 2019 by the authors. Licensee MDPI, Basel, Switzerland. This article is an open access article distributed under the terms and conditions of the Creative Commons Attribution (CC BY) license (http:/ / creativecommons.org/licenses/by/4.0/). 